\title{
Türkiye'deki Tıp Fakülteleri ile Süleyman Demirel Üniversitesi Tıp Fakültesi Öğrenci Trendinin Değerlendirilmesi
}

\author{
Evaluation of Student Trend in Medical Schools in Turkey and Süleyman \\ Demirel University Medical School
}

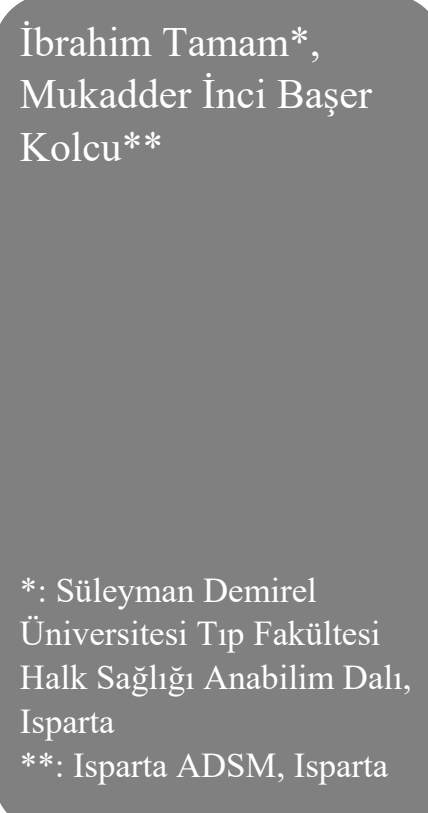

Yazışma Adresi:

Arş. Gör. Dr. İbrahim

Tamam

Adres: Süleyman Demirel

Üniversitesi, Tıp Fakültesi,

Halk Sağlığı Anabilim Dalı,

32260, Isparta, Türkiye

E-mail:

dritamam@gmail.com

Tel: +902462113632

Faks: +90 2462371165
$\ddot{O} z$

Giriş: Sağlık hizmet sunumunda hekim sayısı temel parametrelerdendir. $\mathrm{Bu}$ nedenle tıp fakültelerinde eğitim sürecinin planlanmasında öğrenci sayıları da etkili olmaktadır. Bu planlama sürecinde, ulusal ve yerel hekim eğitim politikaları doğrultusunda çeşitli dönemlerde fakültelerin eğitim olanaklarında düzenlemelere ihtiyaç olmaktadır.

Amaç: $\mathrm{Bu}$ çalışmada Türkiye'deki tıp fakülteleri sayısındaki ve bu fakülteler ile Süleyman Demirel Üniversitesi Tıp Fakültesi'ndeki (SDÜTF) öğrenci sayılarındaki değişimin değerlendirilmesi amaçlanmıştır.

Gereç ve Yöntem: Kesitsel-analitik tipteki bu çalıșmada verilerin toplanmasında Ölçme, Seçme ve Yerleştirme Merkezi istatistikleri, Yükseköğretim Kurulu istatistikleri ve literatürden faydalanılmıştır. Çalışmanın verileri SPSS 17.0 programı ile değerlendirilmiş ve verilerin analizi için parametrik olmayan şartlarda Spearman korelasyon testi kullanılmış̧ır.

Bulgular: Bu çalışmada, 2006-2016 yılları arasında geçen zaman (yıl), bu yıllarda öğrenci alınan tıp fakültelerinin sayısı, yine bu yıllarda Türkiye genelinde tıp fakültelerine alınan öğrenci sayıları ve SDÜTF'ye alınan öğrenci sayılarının her birinin diğer üçü ile arasında çok yüksek düzeyde pozitif anlamlı bir korelasyon olduğu görülmüsstür.

Sonuç: Tıp Fakültesi sayısının artışı ile birlikte öğrenci sayılarındaki artıştan yola çıkılarak, Türkiye'deki hekim sayısında hızlı bir artışın hedeflendiği düşünülebilir. $\mathrm{Bu}$ çalışmada elde edilen bulgular doğrultusunda ülke genelinde tıp fakültelerine alınan öğrenci sayılarındaki hızlı artış sürecinin SDÜTF'ye de yansıdığını söylemek mümkündür.

Tıp eğitimi ile ilgili planlamalarda, ülke genelinde yaşanan ve SDÜTF'ye de yansıyan öğrenci sayılarındaki değişim trendinin göz önünde bulundurulmasının mezuniyet öncesi tıp eğitimi açısından stratejik role sahip olduğu kanaatindeyiz.

Anahtar kelimeler: Tıp, Fakülte, Öğrenci

\begin{abstract}
Introduction: The number of physicians is one of the basic parameters of health care. For this reason, the education process in medical schools is planned in relation to the number of students. In this planning process, in
\end{abstract}


the direction of national and local physician education policies educational facilities of the faculties need to be organized at various periods.

Objective: The aim of this study is to evaluate the change of the number of medical schools in Turkey with the numbers of students in these schools and in Süleyman Demirel University Faculty of Medicine (SDUTF).

Material and Methods: In this cross-sectional analytical study Ölçme, Seçme ve Yerleştirme Merkezi statistics, Yükseköğretim Kurulu statistics and literature has been used for data collection. The data of the study were evaluated with the SPSS 17.0 program and the Spearman correlation test was used for data analysis under nonparametric conditions.

Results: In this study, a positive significant correlation at a very high level was found between 4 parameters. These parameters are; Time elapsed (year) from 2006 to 2016, the numbers of medical schools that received students in these years, numbers of students taken to medical schools throughout Turkey in these years and the numbers of students taken to SDUTF in these years.

Conclusion: It can be considered that a rapid increase in the number of physicians is aimed at by increasing the number of medical schools and increasing the number of students taken to these medical schools. In the direction of the findings obtained in this study, it is possible to say that the rapid increase progress in the number of students taken to the medical schools throughout the country is reflected in to SDUTF.

We believe that considering the trend of change in the student numbers in the whole country with it's reflection to SDUTF has a strategic role in terms of pre-graduate medical education plans.

Keywords: Medical, School, Student

\section{Giriş}

Türkiye'de 2016 y1lı itibariyle 15-24 yaş arasındaki genç nüfus toplam nüfusun $\%$ 16,4'ünü oluşturmaktadır (1). Bu oran ile Türkiye Avrupa bölgesinde Kosova ve Azerbaycan'dan sonra en genç nüfusa sahip olan 3. ülke konumundadır (2). Ülkemizde genç nüfusun yükseköğretime yoğun bir talebi söz konusudur. Uzun yıllardır süregelen bu toplumsal talep yüksekögretimin mezunlara sağladığı avantajlardan kaynaklanmaktadır (3). $\mathrm{Bu}$ avantajlardan en önemlisinin istihdam olduğu söylenebilir. 2016 y1lı Ekonomik İşbirliği ve Kalkınma Örgütü (OECD) göstergelerine göre Türkiye'de üniversite mezunu 25-64 yaş arası kadın ve erkekler ilköğretim ve ortaöğretim mezunlarına göre eğitimsel kazanımlarını daha fazla oranda istihdama dönüştürebilmiştir (4).

Genç nüfusun yükseköğretim talebine karşılık verebilmek ve arz talep dengesini sağlayabilmek amacıyla ülkemizde son yıllarda yeni üniversiteler kurulmuş ve üniversite kontenjanlarında artışa gidilmiştir. Yükseköğretimde son 10 yillık dönemdeki büyüme dikkat çekici boyuttadır. 2006 yılında 93 olan üniversite say1s1 ve 2,5 milyonu geçmeyen yükseköğretimdeki toplam öğrenci sayısı, 2016 y1lına gelindiğinde 183 üniversiteye ve 7 milyondan fazla ögrenciye ulaşmıştır $(5,6,7,8)$. Yükseköğretimdeki bu büyümeye paralel olarak son yıllarda ülke genelinde yeni tıp fakülteleri de açılmış, tıp fakültelerine alınan öğrenci sayılarında da önemli artışa gidilmiştir.

$\mathrm{Bu}$ çalışmada Türkiye'deki tıp fakültelerinin sayısı, bu fakültelerdeki öğrenci sayıları ve SDÜTF'deki öğrenci sayılarının 2006-2016 yılları arasındaki değişiminin değerlendirilmesi amaçlanmıştır.

\section{Gereç ve Yöntem}

Kesitsel-analitik tipteki bu çalışma 1-31 Temmuz 2017 tarihleri arasında Süleyman Demirel Üniversitesi Tıp Fakültesinde gerçekleştirilmiştir. Verilerin toplanması için 
Ölçme, Seçme ve Yerleştirme Merkezi (ÖSYM) istatistikleri, Yükseköğretim Kurulu (YÖK) istatistikleri ve literatürden faydalanılmıştır. Çalışmanın verileri SPSS (Statistical Package for the Social Sciences) 17.0 programı ile değerlendirilmiş ve verilerin analizi için parametrik olmayan şartlarda Spearman korelasyon testi kullanılmıştır.

\section{Bulgular}

Türkiye'de 1980'li yıllardan başlayarak her on yılda bir yaklaşık 2 katına çıkan tıp fakültesi sayısında özellikle 1990-2000 arasında önemli bir artış yaşanmış, 2002-2006 döneminde bu artış yavaşlamış ve 2006 yılından sonra yeniden çok sayıda tıp fakültesi açılmıştır. Bin dokuz yüz yetmiş yılında 9 olan Türkiye'deki tıp fakültesi sayıs1, 1980 yılında 19, 1990 yılında
25, 2000 yılında 47 olmuş, 2002 ve 2006 yılları arasında sayı sabit kalmıştır (9). İki bin altı yılından sonra sayıda yeniden hızlı bir artış görülmüss ve 2016 yılına gelindiğinde Türkiye genelinde ÖSYM'ce öğrenci alınan tıp fakültelerinin sayısı 81'e ulaşmıştır (10). Geçmişten bugüne Türkiye genelinde tıp fakültelerine alınan öğrenci sayılarının değişimine bakıldığında, 1975 yılında 1917 olan sayının sürekli bir artış göstererek 1985 yılında 5440'a ulaştı̆ğ, 2000 yılına gelene kadar 5231 ve 4161 öğrenci sayısı arasında inişli çıkışlı bir seyir izlediği görülebilir (9). İki bin-2009 yılları arasında artış eğiliminde olan sayı, 2009 yılında ani olarak 6568'e yükselmiş ve bu yilda başlayan hızlı artış süreci günümüze kadar devam etmiştir (11). İki bin on altı yılında bu sayı 13924'e ulaşmıştır (12). Türkiye genelinde tıp fakültelerinde okuyan

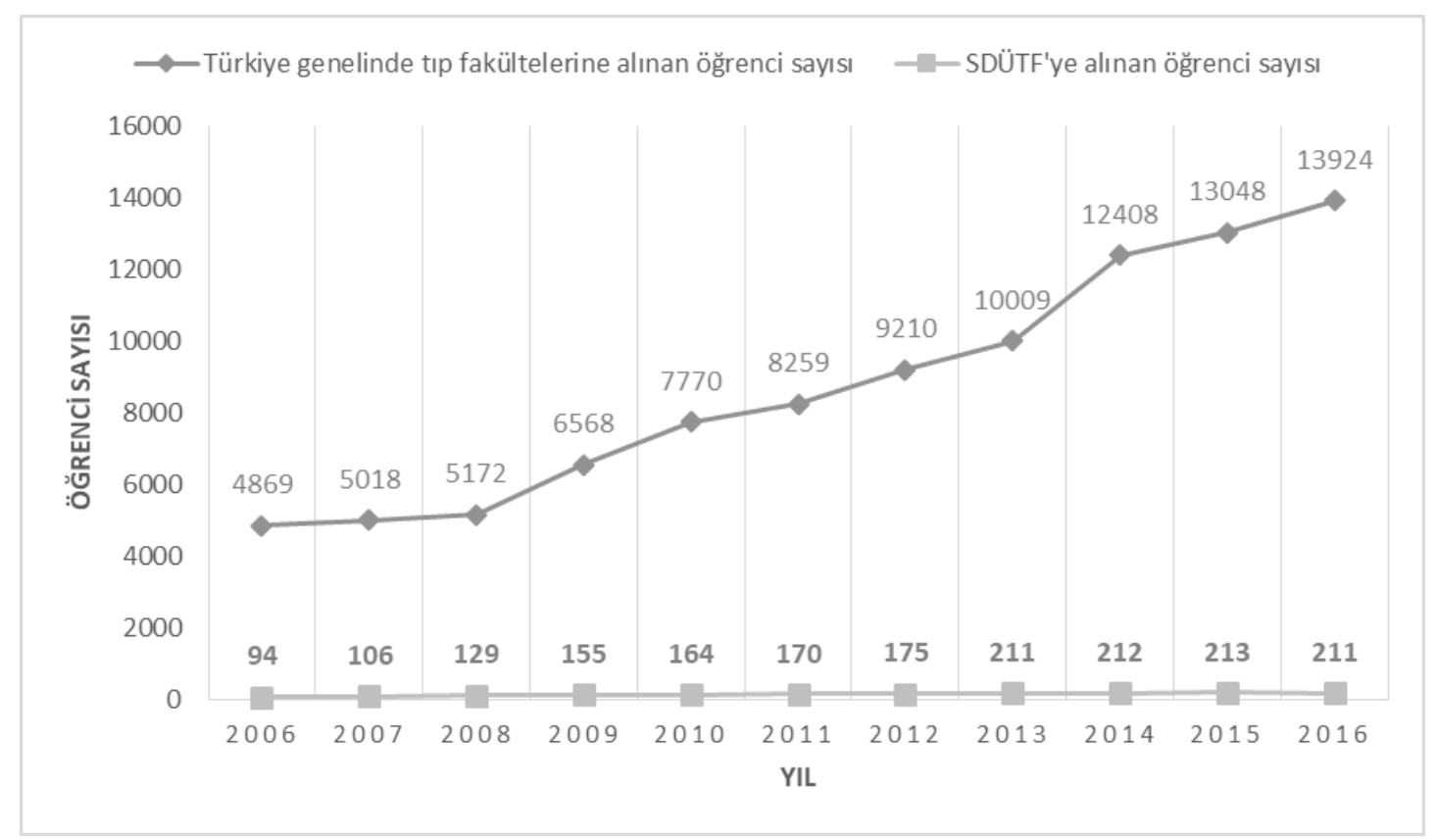

Şekil 1. Türkiye genelinde tıp fakültelerine ve SDÜTF'ye alınan öğrenci
sayılarında yıllara göre değişim (2006-2016)

Kaynak: ÖSYM T.C. Ölçme, Seçme ve Yerleştirme Merkezi. Araştırma, Yayın ve İstatistikler. Süreli Yayınlar (14). YÖK. Yükseköğretim Kurulu. Yükseköğretim Bilgi Yönetim Sistemi. Yükseköğretim İstatistikleri (15). 
Tablo 1. Türkiye genelinde ÖSYM'ce öğrenci alınan tıp fakülteleri sayılarının, Türkiye genelinde tıp fakültelerine alınan ve bu fakültelerde öğrenim gören toplam öğrenci sayılarının, SDÜ Tıp Fakültesi'ne alınan ve öğrenim gören toplam öğrenci sayılarının yıllara göre dağılımı

\begin{tabular}{|c|c|c|c|c|c|}
\hline \multirow[b]{2}{*}{ Yll } & \multirow{2}{*}{$\begin{array}{c}\text { Türkiye Genelinde } \\
\text { ÖSYM'ce } \\
\text { Öğgrenci Alınan } \\
\text { Tıp Fakültelerinin } \\
\text { Sayısı }\end{array}$} & \multicolumn{2}{|c|}{$\begin{array}{l}\text { Türkiye Genelinde } \\
\text { Tıp Fakülteleri }\end{array}$} & \multicolumn{2}{|c|}{ SDÜTF } \\
\hline & & $\begin{array}{l}\text { Alınan } \\
\text { Öğrenci } \\
\text { Sayısı }\end{array}$ & $\begin{array}{c}\text { Öğrenim Gören } \\
\text { Toplam Öğrenci } \\
\text { Sayısı }\end{array}$ & $\begin{array}{c}\text { Alınan Öğrenci } \\
\text { Sayısı }\end{array}$ & $\begin{array}{c}\text { Öğrenim Gören } \\
\text { Toplam Öğrenci } \\
\text { Sayısı }\end{array}$ \\
\hline 2006 & 46 & 4869 & 32166 & 94 & 435 \\
\hline 2007 & 48 & 5018 & 32781 & 106 & 495 \\
\hline 2008 & 55 & 5172 & 33107 & 129 & 579 \\
\hline 2009 & 60 & 6568 & 34856 & 155 & 673 \\
\hline 2010 & 62 & 7770 & 37812 & 164 & 733 \\
\hline 2011 & 69 & 8259 & 41048 & 170 & 832 \\
\hline 2012 & 72 & 9210 & 45732 & 175 & 916 \\
\hline 2013 & 78 & 10009 & 50733 & 211 & 1037 \\
\hline 2014 & 82 & 12408 & 58952 & 212 & 1183 \\
\hline 2015 & 83 & 13048 & 67197 & 213 & 1256 \\
\hline 2016 & 81 & 13924 & 73522 & 211 & 1487 \\
\hline
\end{tabular}

Kaynak: ÖSYM T.C. Ölçme, Seçme ve Yerleştirme Merkezi. Araştırma, Yayın ve İstatistikler. Süreli Yayınlar (14). YÖK. Yükseköğretim Kurulu. Yükseköğretim Bilgi Yönetim Sistemi. Yükseköğretim İstatistikleri (15).

toplam öğrenci sayısı, 2006 yılında 32166 iken 2016 yılında 73522'ye yükselmiştir $(12,13)$. (Tablo 1) (Şekil 1).

İki bin altı ve 2016 yılları arasında Yükseköğretim Kurulu (YÖK)'ten her y1l için 100 öğrenci talebinde bulunulan SDÜTF'de, fakülteye alınan öğrenci sayısında 2006 ve 2016 yılları arasında \%124,4'lük bir artıș yaşanmıştır. İki bin altı yılında fakülteye 94 öğrenci alınmışken 2007 yılında 106, 2008 y1lında 129, 2009 y1lında 155, 2010 y1lında 164, 2011 y1lında 170, 2012 y1lında 175, 2013 yılında 211, 2014 yilında 212, 2015 y1lında 213 ve 2016 yılında 211 öğrenci alınmıștır. Bin dokuz yüz doksan üç-1994 eğitim öğretim yılında 37 öğrenci ile eğitime başlayan
SDÜTF'de, fakültede okuyan toplam öğrenci sayıs1 ise 2006-2016 y1lları arasinda \% 241,8 artmıştır. İki bin altı yılında 435 olan toplam öğrenci sayısı 2007 yılında 495'e, 2008 yılında 579'a, 2009 y1lında 673'e, 2010 y1lında 733'e, 2011 y1lında 832'ye, 2012 y1lında 916'ya, 2013 yılında 1037'ye, 2014 yılında 1183'e, 2015 yilinda 1256'ya ve son olarak 2016 yilina gelindiğinde de 1487'ye ulaşmıștır (Tablo 1) (Șekil 2).

$\mathrm{Bu}$ çalışmada, 2006-2016 yılları asında yıl bazında geçen zaman, 2006-2016 yılları arasında ÖSYM'ce öğrenci alınan tıp fakültelerinin sayısı, 2006-2016 yılları arasında Türkiye genelinde tıp fakültelerine alınan öğrenci sayıs1 ve 2006-2016 y1lları arasında 


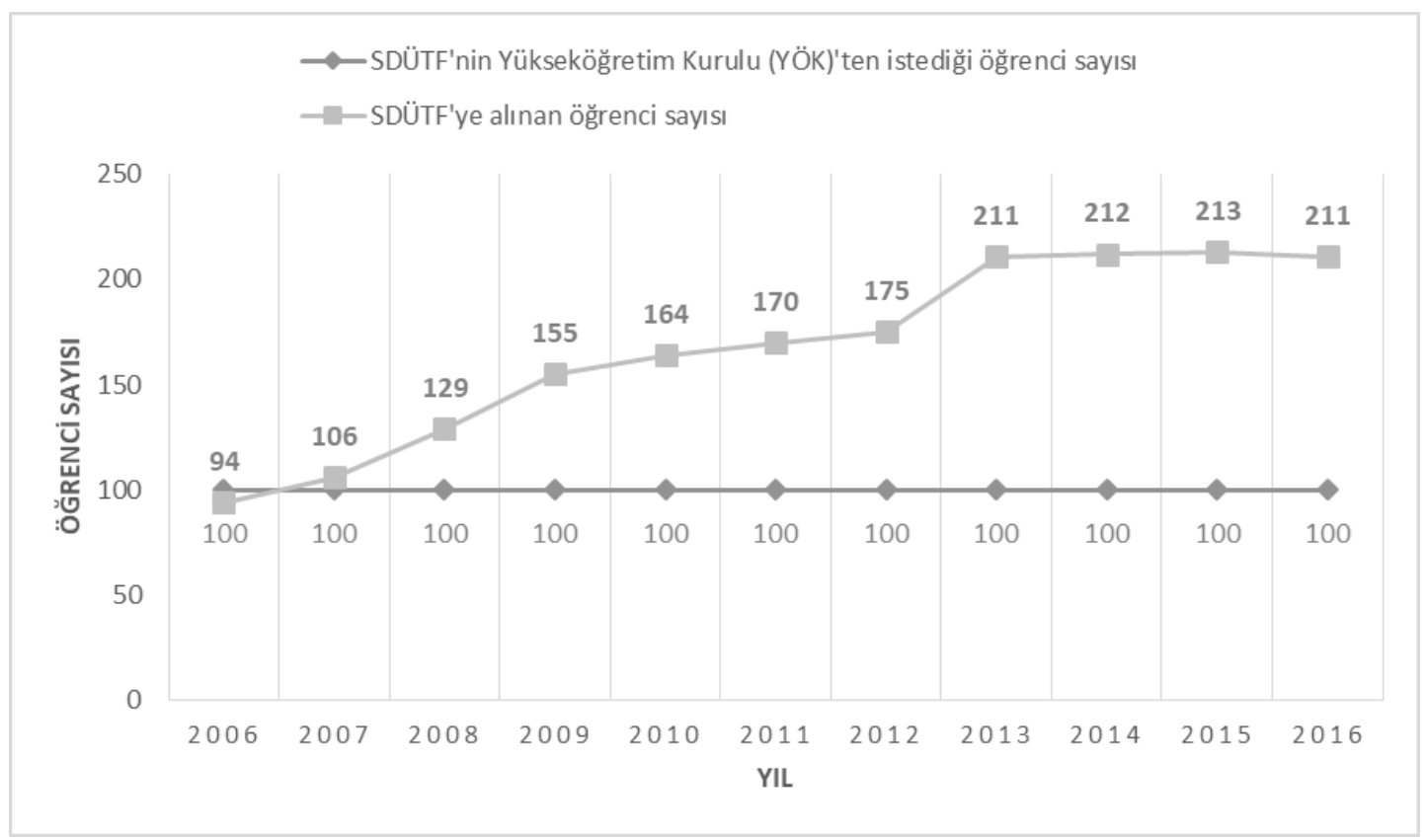

\section{Şekil 2. SDÜTF'nin YÖK'ten talep ettiği öğrenci sayısında ve SDÜTF'ye alınan öğrenci sayısında yıllara göre değişim (2006-2016)}

Kaynak: ÖSYM T.C. Ölçme, Seçme ve Yerleştirme Merkezi. Araştırma, Yayın ve İstatistikler. Süreli Yayınlar (14). YÖK. Yükseköğretim Kurulu. Yükseköğretim Bilgi Yönetim Sistemi. Yükseköğretim İstatistikleri (15).

SDÜTF'ye alınan öğrenci sayılarının her birinin diğer üçü ile arasında çok yüksek düzeyde, pozitif anlamlı bir korelasyon olduğu saptanmıştır. İki bin altı-2016 yılları asında yıl bazında geçen zaman arttıça 2006-2016 yılları arasında ÖSYM'ce öğrenci alınan tıp fakültelerinin sayısı, 2006-2016 yılları arasında Türkiye genelinde tıp fakültelerine alınan öğrenci sayısı ve 2006-2016 yılları arasında SDÜTF'ye alınan öğrenci sayısı artmaktaydı (sirasiyla rho $=0,973 ; \quad \mathrm{p}<0,001, \quad \mathrm{rho}=1,000$; $\mathrm{p}<0,001, \mathrm{rho}=0,961 ; \mathrm{p}<0,001)$. İki bin alt1-2016 yılları arasında ÖSYM'ce ögrrenci alınan tıp fakültelerinin sayısı arttıkça 2006-2016 yılları asında y1l bazında geçen zaman, 2006-2016 yılları arasında Türkiye genelinde tıp fakültelerine alınan öğrenci sayısı ve 20062016 y1lları arasında SDÜTF'ye alınan öğrenci say1s1 artmaktayd1 (sirasiyla $\mathrm{rho}=0,973$; $\mathrm{p}<0,001, \quad \mathrm{rho}=0,973 ; \quad \mathrm{p}<0,001, \quad \mathrm{rho}=0,998$; $\mathrm{p}<0,001)$. İki bin altı - 2016 yılları arasında Türkiye genelinde tıp fakültelerine alınan öğrenci sayısı arttıkça 2006-2016 yılları asında yıl bazında geçen zaman, 2006-2016 yılları arasında ÖSYM'ce öğrenci alınan tıp fakültelerinin sayıs1 ve 2006-2016 yıllar1 arasında SDÜTF'ye alınan öğrenci sayısı artmaktayd 1 (sirasiyla $\mathrm{rho}=1,000 ; \mathrm{p}<0,001$, rho=0,973; $<<0,001$, rho $=0,961 ; p<0,001)$. İki bin alt1-2016 y1lları arasında SDÜTF'ye alınan ögrrenci sayısı arttıkça 2006-2016 yılları asında y1l bazında geçen zaman, 2006-2016 yılları arasında ÖSYM'ce öğrenci alınan tıp fakültelerinin sayısı ve 2006-2016 yılları arasında Türkiye genelinde tıp fakültelerine alınan öğrenci sayısı artmaktaydı (sırasıyla rho=0,961; $\quad \mathrm{p}<0,001, \quad$ rho $=0,998 ; \quad \mathrm{p}<0,001$, rho $=0,961 ; p<0,001$ ) (Tablo 2). 
Tablo 2. 2006-2016 yılları arasında yıl bazında geçen zamanın, bu yıllar arasında Türkiye genelinde ÖSYM'ce öğrenci alınan tıp fakültelerinin sayısının, bu yıllar arasında Türkiye genelinde tıp fakültelerine alınan öğrenci sayısının ve bu yıllar arasında SDÜTF'ye alınan öğrenci sayılarının birbirlerine göre korelasyonları

\begin{tabular}{|c|c|c|c|c|}
\hline & $\begin{array}{c}\text { Yll (2006-2016) } \\
\text { rho ; p }\end{array}$ & $\begin{array}{l}\text { 2006-2016 Yılları } \\
\text { arasında Türkiye } \\
\text { genelinde ÖSYM'ce } \\
\text { öğrenci alınan tıp } \\
\text { fakültelerinin sayısı } \\
\text { rho ; p }\end{array}$ & $\begin{array}{c}\text { 2006-2016 Yılları } \\
\text { Arasında Türkiye } \\
\text { Genelinde Tıp } \\
\text { Fakültelerine } \\
\text { Alınan Öğrenci } \\
\text { Sayısı } \\
\text { rho ; p } \\
\end{array}$ & $\begin{array}{c}\text { 2006-2016 Yılları } \\
\text { Arasında } \\
\text { SDÜTF'ye } \\
\text { Alınan Öğrenci } \\
\text { Sayısı } \\
\text { rho ; p } \\
\end{array}$ \\
\hline Yıl (2006-2016) & & 0,$973 ;<0,001$ & 1,$000 ;<0,001$ & 0,$961 ;<0,001$ \\
\hline $\begin{array}{l}\text { 2006-2016 Yılları } \\
\text { arasında Türkiye } \\
\text { genelinde ÖSYM'ce } \\
\text { öğrenci alınan tıp } \\
\text { fakültelerinin sayısı }\end{array}$ & 0,$973 ;<0,001$ & & 0,$973 ;<0,001$ & 0,$998 ;<0,001$ \\
\hline $\begin{array}{l}\text { 2006-2016 Yılları } \\
\text { Arasında Türkiye } \\
\text { Genelinde Tıp } \\
\text { Fakültelerine } \\
\text { Alınan Öğrenci } \\
\text { Sayısı }\end{array}$ & 1,$000 ;<0,001$ & 0,$973 ;<0,001$ & & 0,$961 ;<0,001$ \\
\hline $\begin{array}{l}\text { 2006-2016 Yılları } \\
\text { Arasında } \\
\text { SDÜTF'ye } \\
\text { Alınan Öğrenci } \\
\text { Sayısı }\end{array}$ & 0,$961 ;<0,001$ & 0,$998 ;<0,001$ & 0,$961 ;<0,001$ & \\
\hline
\end{tabular}

\section{Tartışma ve Sonuç}

Tıp fakülteleri en etkin eğitimi verebilecekleri azami öğrenci sayılarını belirlemekte ve her yıl talep ettikleri öğrenci sayısını YÖK'e bildirmektedir. Fakültelerin sahip olduğu hedefler, yürüttükleri eğitim programının özellikleri ve altyapı kapasitesi ile ilişkili olarak en etkin eğitimi verebilecekleri azami öğrenci sayıları farklılık gösterebilir. İnsan gücü ve öğrenme ortamı altyapısı gibi kurumsal olanakları en etkin şekilde kullanabilmek adına öğrenci alımında izlenen ulusal düzeydeki politikalara hazırlıklı olmak tıp fakülteleri için önem arz etmektedir (16).

$\mathrm{Bu}$ araştırmanın sonunda tıp fakültelerinin sayısı ile tıp fakültelerine alınan öğrenci sayıları arasındaki korelasyondan yola çıkılarak, son 10 yılda Türkiye'deki hekim sayısında hızlı bir artışın hedeflendiği söylenebilir. $\mathrm{Bu}$ çalışmada elde edilen bulgular doğrultusunda, 2009 y1lında ülke genelinde başlayan tıp fakültelerine alınan öğrenci sayılarındaki hızlı artış sürecinin SDÜTF'ye de yansıdığını söylemek mümkündür.

Ülke genelinde yaşanan ve SDÜTF'ye de yansıyan öğrenci sayılarındaki değişim trendinin göz önünde bulundurulmasının mezuniyet öncesi tıp eğitimi ile ilgili planlamalar açısından stratejik role sahip olduğu kanaatindeyiz. 


\section{Kaynaklar}

1. Türkiye İstatistik Kurumu, Haber Bülteni, İstatistiklerle Gençlik 2015. [http://www.tuik.gov.tr/ PreHaberBultenleri.do?id=21517] adresinden 17.07.2017 tarihinde erişilmiştir.

2. Eurostat, Population By Age Group, Proportion Of Population Aged 15-24 Years. [http:// ec.europa.eu/eurostat/tgm/refreshTableAction.do? ta $=$ table \&plugin $=1 \&$ pcode $=$ tps $00010 \&$ language $=e$ n] adresinden 31.07.2017 tarihinde erişilmişsir.

3. Özer M. Türkiye'de yükseköğretimde büyüme ve öğretim üyesi arzı. Yükseköğretim ve Bilim Dergisi 2011; 1(1): 23-26.

4. Education at a Glance 2016: OECD Indicators, Turkey - Country Note. [http://www.keepeek.com/ Digital-Asset-Management/oecd/education/ education-at-a-glance-2016/turkey_eag-2016-84en\#.WX8LDeXyiUk\#page4] adresinden 31.07.2017 tarihinde erişilmiştir.

5. Doğramacı İ. "Türkiye'de ve dünyada yükseköğretim yönetimi." Ankara. Meteksan A.Ș. 2007.

6. ÖSYM T.C. Ölçme, Seçme ve Yerleștirme Merkezi. Araştırma Yayın ve İstatistikler, Süreli Yayınlar, 2007 Y11 Yayınları, 2006-2007 Öğretim Y11 Yükseköğretim İstatistikleri Kitabı, Öğrenci Sayılar1 Özet Tablosu. [http://www.osym.gov.tr/ Eklenti/3992,1 ogrencisaypdf.pdf?0] adresinden 31.07.2017 tarihinde erişilmiştir.

7. YÖK. Yükseköğretim Kurulu. Yükseköğretim Bilgi Yönetim Sistemi. Yükseköğretim İstatistikleri. [https://istatistik.yok.gov.tr/ yuksekogretimIstatistikleri/2017/2017_T107.pdf] adresinden 31.07.2017 tarihinde erișilmiștir.

8. YÖK. Yükseköğretim Kurulu. Yükseköğretim Bilgi Yönetim Sistemi. Yükseköğretim İstatistikleri. [https://istatistik.yok.gov.tr/

yuksekogretimIstatistikleri/2017/2017_T1.pdf] adresinden 31.07.2017 tarihinde erișilmiştir.

9. Sayek İ, Odabaş1 O, Kiper N. Türk Tabipleri Birliği Mezuniyet Öncesi Tip Eğitimi Raporu 2010. Birinci Bask1, Aralık 2010, Türk Tabipler Birliği Yayınları.
10. ÖSYM T.C. Ölçme, Seçme ve Yerleştirme Merkezi. Araştırma, Yayın ve İstatistikler. Süreli Yayınlar. 2016-ÖSYS Yükseköğretim Programlarının Merkezi Yerleştirmedeki En Küçük ve En Büyük Puanlar1 Kitab1. [http://www.osym.gov.tr/ TR, 12735/2016-osys-yuksekogretimprogramlarinin-merkezi-yerlestirmedeki-en-kucukve-en-buyuk-puanlari-kitabi.html] adresinden 31.07.2017 tarihinde erişilmiştir.

11. ÖSYM T.C. Ölçme, Seçme ve Yerleştirme Merkezi. Araştırma Yayın ve İstatistikler, Süreli Yayınlar, 2009 Y1lı Yayınları, 2008-2009 Öğretim Y111 Yükseköğretim İstatistikleri Kitab1. [http:// www.osym.gov.tr/

Eklen-

ti/4171,13ogretimalanlisansogrencisaypdf.pdf?0] adresinden 31.07.2017 tarihinde erişilmiştir.

12. YÖK. Yükseköğretim Kurulu. Yükseköğretim Bilgi Yönetim Sistemi. Yükseköğretim İstatistikleri [https://istatistik.yok.gov.tr/ yuksekogretimIstatistikleri/2016/2016_T17.pdf] adresinden 31.07.2017 tarihinde erișilmiștir.

13. ÖSYM T.C. Ölçme, Seçme ve Yerleştirme Merkezi. Araştırma Yayın ve İstatistikler, Süreli Yayınlar, 2006 Y1lı Yayınları, 2005-2006 Öğretim Y111 Yükseköğretim İstatistikleri Kitabı. [http:// www.osym.gov.tr/Eklenti/3971,13undigpdf.pdf?0] adresinden 31.07.2017 tarihinde erişilmiştir. 14. ÖSYM T.C. Ölçme, Seçme ve Yerleştirme Merkezi. Araştırma, Yayın ve İstatistikler. Süreli Yayınlar. [http://www.osym.gov.tr/TR,6552/sureliyayinlar.html] adresinden 31.07.2017 tarihinde erişilmiştir.

15. YÖK. Yükseköğretim Kurulu. Yükseköğretim Bilgi Yönetim Sistemi. Yükseköğretim İstatistikleri. [https://istatistik.yok.gov.tr/] adresinden 31.07.2017 tarihinde erişilmiştir.

16. UTEAK - Ulusal Tıp Eğitimi Akreditasyon $\mathrm{Ku}-$ rulu. Mezuniyet Öncesi Tip Eğitimi Ulusal Standartlar1 2014. [http://www.uteak.org.tr/uploads/ belge/MOTE_STANDARTLAR_2014.pdf] adresinden 31.07 .2017 tarihinde erişilmiştir. 